\title{
Friedreich Ataxia
}

National Cancer Institute

\section{Source}

National Cancer Institute. Friedreich Ataxia. NCI Thesaurus. Code C84718.

An autosomal recessive inherited disorder caused by mutations in the FXN gene. It is characterized by progressive degeneration of the nerve tissues of the spinal cord. The main symptoms include gait and balance disturbances, lack of limb coordination, and speech disturbances. 